\title{
Colorimetric-enzymatic determination of tyramine by generation of
}

\section{gold nanoparticles}

\author{
Jesús Navarro ${ }^{1}$, Susana de Marcos ${ }^{1}$ and Javier Galbán ${ }^{1 *}$ \\ ${ }^{1}$ Analytical Chemistry Department, Faculty of Sciences, Aragón Institute of Nanoscience (INA- \\ ICMA), University of Zaragoza, E-50009, Zaragoza, Spain
}

\section{*Corresponding author}

Prof. Javier Galbán

Email: jgalban@unizar.es

\section{ORCID}

Javier Galbán (0000-0002-8973-5104)

Susana de Marcos (0000-0002-7902-6005)

\section{ACKNOWLEDGMENT}

The authors thank the Ministry of Economy and Finance (MINECO) of Spain (CTQ201676846R) and the Research Groups funding of the Government of Aragón (group E25_17R), for financial support. J Navarro thanks the Government of Aragón (DGA) for a grant. The authors are also very grateful to Dr. Francisco Palacios and Cristina Asensio, MsC, of the Public Health Laboratory of Aragón, for their invaluable help. 


\begin{abstract}
In this paper, it has been demonstrated that-Au(III) is able to act instead of $\mathrm{O}_{2}$ in the oxidase enzymatic reaction, so that it becomes reduced to purple gold nanoparticles (AuNPs). The plasmon band (at $540 \mathrm{~nm}$ ) can be used as the analytical signal. Tyramine has been determined using its enzymatic reaction with tyramine oxidase (TAO). The kinetic of the AuNP formation has been studied in the light of both the Avrami equation for crystallization and the FinkeWatsy mechanism for AuNP nucleation and growth. The effects of the Au(III), TAO and tyramine concentrations on the corresponding kinetic constants have been obtained. Working at room temperature, in the optimal conditions (phosphate buffer $\mathrm{pH} 7.0$, TAO $0.5 \mathrm{U}^{\mathrm{mL}} \mathrm{mL}^{-1} \mathrm{Au}(\mathrm{III})$ $1 \mathrm{mM}$ ), the linear response ranges from $2.5 \times 10^{-5} \mathrm{M}$ to $3.3 \times 10^{-4} \mathrm{M}$ Tyramine (5.6\% RSD) and the LOD is $2.9 \times 10^{-6} \mathrm{M}$. In these conditions, the signal is measured after 30 minutes reaction (to obtain the highest sensitivity), but this time can be significantly reduced by increasing the temperature (the reaction is finished after 4 min working at $50{ }^{\circ} \mathrm{C}$ ). The method has been applied to tyramine determination in a cheese sample with good results. The new scheme proposed in this paper can be extended, in principle, to other enzymatic methods based on oxidase enzymes.
\end{abstract}

KEYWORDS: Tyramine; Tyramine Oxidase; HRP; ABTS; TMB; Foodstuff; Cheese 


\section{INTRODUCTION}

Tyramine is a biogenic amine produced by the decarboxylation of the aminoacid tyrosine due to biological activity (microorganisms). It is usually present in foodstuffs in moderate concentrations. High concentrations in foodstuffs of this compound, which can appear due to inadequate manipulation or decomposition, are not suitable for human consumption (its toxic effects include nausea, vomiting, migraines or respiratory disorders) [1]. The tyramine contents in foods is not specifically regulated by law although it is strongly suspected that it helps the histamine concentrations in the human body to increase (the concentration limits of histamine in some foods have been established by the European Union). Moreover, tyramine is the majority biogenic amine in some types of foods and its maximum content in some products is regulated in the corresponding Codex Alimentarius of some countries [2].

The determination of tyramine in foods presents similar difficulties to the analysis of other biological substances: the complexity of the sample matrix and its low concentration. This is why it is almost unavoidable to perform a previous extraction to eliminate the interferences, to concentrate the samples and to apply an instrumental separation technique such as layer chromatography, gas chromatography, capillary electrophoresis or high-resolution liquid chromatography. These methodologies have been described in previous papers $[3,4]$. All these methods work very well, but they need long analysis time and qualified personnel, so they are normally used when several biogenic amines need to be determined. Rapid response methods are necessary for the rapid detection of high levels of tyramine in foods in order to adequately protect consumers, workers and producers. Enzymatic methods of analysis are suitable alternatives in these cases. 
Very few enzymatic reactions work analytically well for tyramine, in particular, those based on Polyamine Oxidase (PAO) and especially Tyramine Oxidase (TAO) [5]. TAO is an oxidase enzyme which catalyzes the oxidation/decarboxylation of tyramine according to the reaction given in Scheme 1. TAO has been used for the development of electrochemical sensors [6,7], but as far as we know, no optical colorimetric or fluorometric methods or sensors have been developed for the determination of this compound.

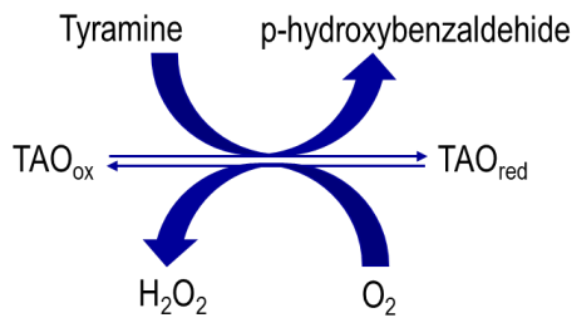

(Scheme 1)

The current strategies used for colorimetric determinations based on oxidase reactions, such as that shown in scheme 1 , consists of coupling an indicating reaction based on horseradish peroxidase (HRP) and a chromogen (TMB, ABTS, or some others) which is oxidized to a colored form (the reduced form is colorless). These reactions generally work well but present some problems [8,9]: a) most dyes are not very stable and can be partially oxidized by the $\mathrm{O}_{2}$ present in the air; $\mathrm{b}$ ) the colored species formed can react with the product of the analyte; c) several reducer species present in the sample can interfere in the dye product formation. News strategies are acquired to avoid these problems are required.

The use of AuNPs as a basis for the development of colorimetric methods has been growing exponentially. Most of these methods are based on using the AuNPs as a substitute for the chromogenic reagent and exploit three fundamental ideas [10,11]: 1) The addition of the analyte causes the aggregation of these nanoparticles so that they change their spectroscopic properties in a way related to the analyte concentration in the 
sample, 2) as a consequence of the enzymatic reaction the AuNPs size increases due to the $\mathrm{H}_{2} \mathrm{O}_{2}$ presence [12]; and 3) The product of the enzymatic is able to form AuNPs [13].

In this paper we propose a different approach which complements these AuNPs methods and solves some of the previously indicated problems caused by chromogens. It consists of synthesizing AuNPs from $\mathrm{Au}(\mathrm{III})$ as a consequence of the enzymatic reaction and measuring the absorbance of the appearing plasmon band (540 $\mathrm{nm})$. Our hypothesis is that $\mathrm{Au}(\mathrm{III})$ can replace $\mathrm{O}_{2}$ in the reaction of Scheme 1 , so it is reduced and AuNPs appear during the enzymatic reaction. Taking advantage of the good selectivity of TAO to tyramine, interference problems are minimized. This has allowed this method to be applied for tyramine determination in a cheese sample. Experimental conditions have been obtained in which the formation of nanoparticles occurs in a few minutes. This method complements one of the three ways in Analytical Nanoscience proposed by Valcarcel [14].

\section{EXPERIMENTAL SECTION}

\subsection{Reagents and solutions}

Tyramine oxidase (TAO) (EC 1.4.3.6) was obtained from Sekisui Diagnosis (https://www.sekisuichemical.com) (4.6 U. $\left.\mathrm{mg}^{-1}\right)$ and dissolved in phosphate buffer $\mathrm{pH}$ 7.0, 0.1 M. The biogenic amines tyramine, cadaverine, putrescine and histamine were obtained from Sigma (https://www.sigmaaldrich.com/spain.html); these amines were weighed and dissolved in the corresponding buffer. Phosphate buffer $(0.1 \mathrm{M})$ was prepared from $\mathrm{Na}_{2} \mathrm{HPO}_{4}$ and $\mathrm{NaH}_{2} \mathrm{PO}_{4}$ solids (Sigma S9763, S9638). Gold(III) chloride hydrate solid (Sigma 254169) was dissolved in miliQ water to obtain a $50 \mathrm{mM}$ solution. 


\subsection{Apparatus}

A Foxy-RTM fluorescence $\mathrm{O}_{2}$ sensor from Ocean Optics (EW Duive, The Netherlands, https://oceanoptics.com/) consisting of a QE65000 CCD-array spectrometer coupled to an oxygen FOXY-R (by A QBIF600-UV/Vis optical fiber), and a LS-450 pulsed blue LED light as radiation source, was used to measure dissolved oxygen. A Tecnai F30H7650 microscope (scanning and transmission mode, STEM) (FEI, The Netherlands, https:// www.fei.com) was used for characterization of the gold nanoparticles. UV-vis molecular absorption measurements were performed on a Specord 210 Plus spectrophotometer and an Agilent 8453 diode array spectrophotometer (One cm cuvettes were used in all cases). A Thermo Scientific Multifuge X1R centrifuge was used for separation by centrifugation. The Millipore MiliQ $\mathrm{H}_{2} \mathrm{O}$ system was used for water purification.

\subsection{Sample treatment}

Ten grams of Emmental cheese were weighed and mechanically ground with $20 \mathrm{~mL}$ of trichloroacetic acid (TCA) 5\% (w/V). The mixture was stirred for $30 \mathrm{~min}$ and subsequently centrifuged for $20 \mathrm{~min}$ at $5000 \mathrm{rpm}$ at $4{ }^{\circ} \mathrm{C}$. The supernatant was collected and $2 \mathrm{~mL}$ of $2 \mathrm{M} \mathrm{NaOH}$ was added and centrifuged again for $20 \mathrm{~min}$ at $5000 \mathrm{rpm}$ at 4 ${ }^{\circ} \mathrm{C}$. The supernatant was collected and the $\mathrm{pH}$ was adjusted to $\mathrm{pH} 7.0$ with $\mathrm{HCl} 1 \mathrm{M}$. The extract was filtered with a $0.45 \mu \mathrm{m}$ nylon filter and the solution was made up to 25 $\mathrm{mL}$ with miliQ $\mathrm{H}_{2} \mathrm{O}$. This sample solution was used for the determination of tyramine in cheese.

\subsection{Measurement procedure}

$1940 \mu \mathrm{L}$ of the corresponding standard solution (in phosphate buffer $\mathrm{pH}=7.00 .1 \mathrm{M}$ ) and $20 \mu \mathrm{L}$ TAO 0.5 U.mL ${ }^{-1}$ were added in a cuvette. After waiting 5 minutes, $40 \mu \mathrm{L}$ of 50 $\mathrm{mM} \mathrm{HAuCl}_{4}$ were added to the cuvette- The formation of AuNPs was followed by 
measuring the variation of Abs $(540 \mathrm{~nm})$ with time at room temperature and at $40{ }^{\circ} \mathrm{C}$. To perform the kinetic study, spectra were collected every 5 seconds after adding the $\mathrm{HAuCl}_{4}$ solution.

For the determination of tyramine in Emmental cheese, $250 \mu \mathrm{L}$ of the sample solution, $1690 \mu \mathrm{L}$ phosphate buffer $\mathrm{pH}=7.00 .1 \mathrm{M}$ and $20 \mu \mathrm{L}$ TAO $0.5 \mathrm{U} \cdot \mathrm{mL}^{-1}$ were added in a cuvette. After waiting 5 minutes, $40 \mu \mathrm{L}$ of $50 \mathrm{mM} \mathrm{HAuCl}_{4}$ were added to the cuvette and the formation of AuNPs was followed.

\section{RESULTS AND DISCUSSION}

\subsection{Mechanism of the enzymatic reaction in the presence of Au(III).}

The molecular absorption spectra of a solution containing tyramine, TAO and Au(III) changes during the enzymatic reaction, as shown in Figure 1A. As can be seen, after an activation time, a band due to the plasmon resonance appears and increases until a plateau is obtained (Figure 1B). Depending on the experimental conditions used, a later slower increase is observed. Figure S1 (Supporting Information) shows TEM images indicating that the spectra are due to the AuNP formation.

Several hypotheses were considered in order to explain the AuNP formation, before establishing the final mechanism:

i) Intrinsic reducing capabilities of proteins. Some proteins are able to generate $\mathrm{Au}$ nanostructures due to the reducing capability of some aminoacids [15]; however, in this case, no AuNP formation was observed by direct reaction between Au(III) and TAO (Figure S2A).

ii) Intrinsic reducing capabilities of tyramine. Previous papers have shown that AuNP can be formed by direct reaction between nitrogenated compounds and $\mathrm{Au}(\mathrm{III})$ [16]. The direct reaction between tyramine and $\mathrm{Au}(\mathrm{III})$ was thoroughly studied but no AuNP 
formation was observed. It is only when using a large amount of tyramine that a black $\mathrm{Au}^{0}$ precipitate appears after several hours of reaction, giving a small signal (Figure S2B). This study was also carried out in the presence of albumin but no changes were observed (Figure S2C).

iii) $\underline{\mathrm{AuNP}}$ growth induced by $\mathrm{H}_{2} \underline{\mathrm{O}}_{2}$. Several authors have indicated that $\mathrm{H}_{2} \mathrm{O}_{2}$ is able to increase the growth of previously formed AuNP $[12,17]$. Thus, the $\mathrm{Au}^{0}$ nucleus can be formed by direct reduction of $\mathrm{Au}(\mathrm{III})$ with tyramine, where $\mathrm{H}_{2} \mathrm{O}_{2}$ assists the AuNP growth. To test this, the enzymatic reaction was carried out in the presence of catalase (Figure S3) to remove the $\mathrm{H}_{2} \mathrm{O}_{2}$ formed during the enzymatic reaction. The catalase produced rather the opposite effect, increasing the kinetic of AuNP formation and reducing the width of the spectra. Moreover, catalase increases the rate of the AuNP formation, which indicates that $\mathrm{H}_{2} \mathrm{O}_{2}$ actually hinders the process. iv) $\underline{\mathrm{Au}(\mathrm{III}) \text { versus } \mathrm{O}_{2}}$. Finally, as shown below, the kinetic of the AuNP formation increases when the tyramine concentration is higher than that of the $\mathrm{O}_{2}$ (i.e. the whole $\mathrm{O}_{2}$ of the solution is consumed), indicating that the $\mathrm{Au}(\mathrm{III})$ participates in the enzymatic reaction. The possibility that metallic ions can act as substrates of enzymes has recently been reported [18].

All these studies reinforce the idea that the active center of the enzyme is responsible for the AuNP. According to this, Au(III) is reduced to gold nanoparticles and the catalytic center of the enzyme is oxidized to its initial state. TAO is an enzyme belonging to the copper-containing amine oxidases group. The kinetic mechanism of this type of enzyme has been studied [19] (not specifically with TAO) and is summarized in figure $\mathrm{S} 4$. As can be seen, during the reaction $\mathrm{Cu}$ (II) can be reduced to $\mathrm{Cu}(\mathrm{I})$ and it is reoxidized back by $\mathrm{O}_{2}$. Since $\mathrm{Cu}(\mathrm{I})$ is also able to reduce $\mathrm{Au}(\mathrm{III})$ to $\mathrm{Au}^{0}$, this can demonstrate the proposed mechanism. 


\subsection{Kinetics of the AuNP formation: Theoretical background}

In this paper we are interested in providing theoretical support and understanding of the experimental results obtained. Most of the classical mechanisms [20, 21] consider that the formation of nanoparticles is based on the Johnson, Mehl, Avrami and Kolmogorov (JMAK) crystallization model which is given by the general equation:

$$
\frac{\mathrm{Abs}_{\mathrm{t}}}{\mathrm{Abs_{ \infty }}}=1-\mathrm{e}^{-(\mathrm{kt})^{\mathrm{n}}}==>\operatorname{Ln}\left(\operatorname{Ln}\left(\frac{\mathrm{Abs}_{\infty}}{\mathrm{Abs}_{\infty}-\mathrm{Abs}_{\mathrm{t}}}\right)\right)=\mathrm{nLn}\left(\mathrm{K}_{\mathrm{Av}}\right)+\mathrm{nLn}(\mathrm{t})
$$

$A b s_{t}$ and $A b s_{\infty}$ being the absorbance of the plasmon band at any moment and at the end of the reaction respectively, $K_{A v}$ being the overall kinetic constant (Avrami constant) of the AuNP formation reaction and $n$ being a parameter related to the dimensionality and shape of the AuNPs. During the optimization study, the Abst=f(t) representations were fitted to this equation and the corresponding $\mathrm{K}$ values were obtained.

Starting with these principles, Finke-Watzy proposed a kinetic mechanism consisting of two simultaneous steps [22], the first being a slow continuous pseudo-first order reaction describing the formation of nuclei involving the precursor ( $\mathrm{Au}(\mathrm{III})$ in this case) (Eq 2), and a second fast step (Eq 3) comprising an autocatalytic growth of the nuclei with the precursor,

$$
\begin{aligned}
& \mathrm{A} \stackrel{k_{1}}{\Rightarrow} \mathrm{B} \\
& \mathrm{B}+\mathrm{A} \stackrel{k_{2}}{\Rightarrow} 2 \mathrm{~B}
\end{aligned}
$$

They derived an equation relating the $[\mathrm{A}]_{\mathrm{t}}$ concentration with $\mathrm{k}_{1}, \mathrm{k}_{2}$ and $\mathrm{C}_{\mathrm{A}, 0}$ (initial $\mathrm{A}$ concentration):

$$
[A]_{t}=\frac{k_{1}+k_{2} C_{A, 0}}{k_{2} C_{A, 0}+k_{1} e^{\left(k_{1}+k_{2} C_{A, 0}\right) t}} \quad(\mathrm{Eq} 4)
$$

From this equation, both $[\mathrm{B}]_{\mathrm{t}}$ and $[\mathrm{AuNP}]_{\mathrm{t}}$ can be derived. Although other models have been subsequently proposed, the Finke-Watsy mechanism has been extensively used for modeling gold or other nanoparticle formation (and other types of structures, such as 
protein agglomeration) [23]. In most cases, the reducer concentration (necessary for $\mathrm{Au}^{0}$ formation) is in excess of A, so $k_{1}$ and $k_{2}$ are pseudo-first and second order constants, respectively. In our case the reducer is not always in excess relative to $\mathrm{Au}(\mathrm{III})$, but in most cases it is in defect so we have derived two equations to describe the absorbance variation due to AuNP during the reaction $\left(\mathrm{Abs}_{\mathrm{t}}\right)$, both when the concentration of $\mathrm{Au}(\mathrm{III})$ is higher (Eq 5), or lower (Eq 6) than the tyramine concentration (see supplementary material Appendix S1).

$A b s_{t}=\varepsilon_{A u N P}[A u N P]_{t}=\varepsilon_{A u N P, n} \frac{k_{1}}{k_{2, n}}\left(\frac{1-e^{-C_{A u, 0}\left(k_{1}+\frac{2}{3} k_{2, n} C_{\text {tyramine }, 0}\right) t}}{e^{-C_{A u, 0}\left(k_{1}+\frac{2}{3} k_{2, n} C_{\text {tyramine }, 0}\right) t}+\frac{3 k_{1}}{2 k_{2, n} C_{T y r}, 0}}\right)$

$$
A b s_{t}=\varepsilon_{A u N P}[A u N P]_{t}
$$

$$
=\varepsilon_{A u N P, n} \frac{k_{1}}{k_{2, n}}\left(\frac{1-e^{-C_{\text {tyramine }, 0}\left(k_{1}+k_{2, n} C_{A u, 0}\right) t}}{e^{-C_{\text {tyramine }, 0}\left(k_{1}+k_{2, n} C_{A u, 0}\right) t}+\frac{k_{1}}{k_{2, n} C_{A u, 0}}}\right)
$$

where

$$
k_{2, n}=\frac{k_{2}}{n} \quad(E q 7) \quad \varepsilon_{A u N P, n}=\frac{\varepsilon_{A u N P}}{n}
$$

In these equations, $C_{A u, 0}$ and $C_{T y r, 0}$ are the total $\mathrm{Au}(\mathrm{III})$ and tyramine concentrations used, $n$ the number of Au atoms per AuNP and $\varepsilon_{A u N P}$ the molar absorptivity of the AuNPs. Moreover, the stoichiometry of the overall reaction has also been taken into account.

$$
2 \mathrm{Au}(\mathrm{III})+3 \text { Tyramine } \Leftrightarrow 2 \mathrm{Au}^{0}+3 \text { Tyramine }_{\mathrm{ox}}
$$

During the optimization study, the $\mathrm{Abs}=\mathrm{f}(\mathrm{t})$ recorders obtained were fitted to the corresponding equation (Eq 6 or Eq 7) using Solver ${ }^{\circledR}$ and the $k_{2, n}, k_{1}$ y $\varepsilon_{A u N P, n}$ were obtained. 
As has been indicated above (Figure 1B), a later increase in the absorbance at the end of the process was observed, especially when the $\mathrm{Au}(\mathrm{III})$ concentration was in excess. This is usually explained by a further evolution of the formed nanoparticles, which is normally due to one of the following processes [24, 25]: a) Ostwald ripening, according to which smaller nanoparticles formed at the end of the process become dissolved to increase the size of the larger nanoparticles; or b) Oriented attachment, referring to the coalescence of smaller nanoparticles to give larger ones. While we have no direct experimental evidences of either of these processes, it seems clear that a further reorganization of the AuNP is also produced during the enzymatic reaction. We have applied both models but neither of them properly fitted our results, so no further discussion on this part of the curve is given in this paper (see Figure S5).

\subsection{Optimization of the analytical method}

Although $\mathrm{Au}(\mathrm{III})$ is able to replace $\mathrm{O}_{2}$ in the reaction, the enzyme is more prone to react with $\mathrm{O}_{2}$ than with $\mathrm{Au}(\mathrm{III})$. This is observed when $\mathrm{Au}(\mathrm{III})$ is added at different times (incubation time) from the beginning of the reaction (see Figure 2). As can be seen, the longer the delayed time (up to $5 \mathrm{~min}$ ), the faster the reaction, which indicates that, when $\mathrm{Au}(\mathrm{III})$ is added, the lower the $\mathrm{O}_{2}$ concentration in the solution, the faster the reaction. However, for 8 min incubation time the reaction becomes slower, which can be explained considering that the $\mathrm{O}_{2}$ has diffused back from the environment surrounding the cuvette. The calculated kinetic constants $k_{l}$ and $k_{2, n}$ (table S1) show that the $\mathrm{O}_{2}$ mainly affect the AuNP growth. Five minutes was chosen as the optimum incubation time.

Since this type of method has not been previously reported, it was considered necessary to study the effect of experimental variables on the AuNP formation. In the framework of the AuNP formation during the reaction, the following results were considered of 
interest: A) maximum wavelength $(\lambda \max )$ and bandwidth $(\Delta \lambda$, taken as the width at half of the maximum) of the plasmon band, as a measurement of the AuNP size $[26,27]$; B) maximum absorbance $\left(\mathrm{Abs}_{\max }\right)$ (also the $\varepsilon_{\mathrm{AuNP}, \mathrm{n}}$ at $\left.\lambda_{\max }\right)$ before ripening, as a measurement of the analytical method sensitivity; and C) kinetic of the reaction (represented by the $K_{A v}, k_{l}$ and $k_{2, n}$ values).

The most critical parameter affecting the AuNP formation during the enzymatic reaction are the $\mathrm{Au}(\mathrm{III}), \mathrm{TAO}$ and tyramine (the analyte) concentrations. Tables S2-S4 compile the $\mathrm{Abs}_{\max }, \lambda_{\max }, \Delta \lambda, \mathrm{k}_{1}, \mathrm{k}_{2, \mathrm{n}}, \varepsilon_{\mathrm{AuNP}, \mathrm{n}}$ and $\mathrm{K}_{\mathrm{Av}}$ values obtained during the optimization studies of these parameters. The following conclusions can be derived from these studies:

1) By increasing the concentration of TAO (Figure 3), the polydispersity of the AuNPs increase and as a consequence, the $\Delta \lambda$.

2) $\lambda$ max depends on the TAO (Figure 3) and tyramine concentrations, but in opposite senses. Although new assays are necessary to properly explain these results, a first hypothesis can be made. It is accepted that the longer the wavelength the higher the AuNP diameter [28,29]. However, the TEM images (Figure S1) indicated that the AuNP diameter does not appreciably change with the enzyme concentration. Thus, the $\lambda$ max displacement can be attributed to the interaction between the AuNP and the protein, which according to the bibliography produces a red shift of the plasmon band [30]. Regarding the tyramine effect, probably the tyramine product of the reaction can take part of the outer sphere of the AuNP, so the spectra wavelength will be affected. 3)-The overall kinetic of the reaction (see $K_{A v}$ value) is favored, as expected, by medium-high TAO and tyramine concentrations, but the effect of both parameters on $\mathrm{k}_{1}$ and $\mathrm{k}_{2, \mathrm{n}}$ is different. While TAO stimulates the growth step, tyramine increases the nucleation step. The effect of the $\mathrm{Au}(\mathrm{III})$ is of interest: $\mathrm{K}_{\mathrm{Av}}$ is nearly constant up to an 
$\mathrm{Au}(\mathrm{III})$ concentration close to the $\mathrm{O}_{2}$ saturation concentration $\left(\mathrm{O}_{2, \text { sat }}\right)$ in water, but higher $\mathrm{Au}(\mathrm{III})$ values produce a decrease in the overall kinetic reaction. Similarly, $\mathrm{k}_{1}$ gives a maximum at $\mathrm{O}_{2 \text {,sat }}$ then decreases, but $\mathrm{k}_{2, \mathrm{n}}$ decreases monotonically with the $\mathrm{Au}(\mathrm{III})$ concentration. These results seems to indicate that $\mathrm{Au}(\mathrm{III})$ is of course necessary for AuNP formation, but it can act as an inhibitor of the enzymatic reaction.

4) The effect of $\mathrm{Au}(\mathrm{III})$ and TAO on the Abs $\mathrm{Abx}_{\text {ax }}$ is also indicated in Tables S2 and S3, and can be explained considering the variations observed in the corresponding $\varepsilon_{\text {AuNP,n }}$. The Mie theory predicts a relationship between this parameter and the cubed AuNP diameter raised to the cube $\left(\mathrm{d}^{3}\right)$ [31]. This relationship has been experimentally observed [31,32]; an average relation is given by (see Appendix S2):

$$
\varepsilon_{A u N P}=9.2( \pm 4.1) \times 10^{4} d^{3} \quad(d, \text { in } n m) \quad(E q 10)
$$

If it is considered that AuNPs are spherical in shape, it is possible to relate $\mathrm{d}$ with the number of $\mathrm{Au}$ atoms present in each AuNP according to the following equation [33]:

$$
n=30.9 d^{3}(d, \text { in } n m) \quad(\text { Eq 11) }
$$

By combining equations (10) and (11) the expected $\varepsilon_{\text {AuNP,n }}$ value can be obtained:

$$
\varepsilon_{A u N P, n}=\frac{\varepsilon_{A u N P}}{n}=3.0( \pm 1.3) \times 10^{3}(\mathrm{Eq} 12)
$$

The values given in tables S2-S4 qualitatively (i.e., order of magnitude) agree with (Eq 12), which validates the model given by equations (5) and (6); the differences observed between the theoretical value given in Eq12 and those obtained experimentally can be explained considering that the AuNP are not fully spherical (Fig S1). Moreover, equation (10) states that changes in the observed $\varepsilon_{A u N P, n}$ may be due to small variations in the $\mathrm{d}$ of the formed AuNP.

In order to obtain a suitable balance between kinetics, sensitivity and linear range, the $\mathrm{Au}(\mathrm{III})$ and TAO concentrations chosen were $10^{-3} \mathrm{M}$ and $0.5 \mathrm{U} \cdot \mathrm{mL}^{-1}$ respectively. 
The $\mathrm{pH}$ effect on the TAO enzymatic reaction was studied (figure S6A) and the results were compared with those obtained by measurement of the $\mathrm{O}_{2}$ consumption in the absence of $\mathrm{Au}(\mathrm{III})$ (figure S6B). As can be seen, the enzymatic reaction can be carried out quantitatively in a $\mathrm{pH}$ range from 6 to 10 in the absence of $\mathrm{Au}(\mathrm{III})$, with optimum reaction rates at $\mathrm{pH} 7.0$ and 8.0. When $\mathrm{Au}(\mathrm{III})$ is used, the effect of the $\mathrm{pH}$ is more critical. First, the AuNP formation is observed in a narrower $\mathrm{pH}$ range, from 7.0-9.0; second, the $\mathrm{Abs}_{\max }$ and the kinetic constants of the reaction depend on the $\mathrm{pH}$, with an optimum at $\mathrm{pH} 7.0$; third, the $\lambda_{\max }$ and $\Delta \lambda$ show same dependence on the $\mathrm{pH}$, but 7.0 and 8.0 give similar results.

The AuNP formation is slower than the classical indicating colorimetric reactions based on HRP and a dye. To improve the kinetic of the reaction, the effect of temperature was also studied (Figure 4). As expected, the time necessary to reach the plateau is reduced by increasing the temperature. At a temperature of $60^{\circ} \mathrm{C}$, after the fast increase in the absorbance a later decrease is observed due to the enzyme denaturation which destabilizes the AuNP formed. The three kinetic constants $\left(\mathrm{k}_{1}, \mathrm{k}_{2, \mathrm{n}}\right.$ and $\left.\mathrm{K}_{\mathrm{Av}}\right)$ increase with the temperature following the Arrhenius equation (Table S5), but its effect on the $\mathrm{Abs}_{\max }, \lambda_{\max }$ and $\Delta \lambda$ is negligible.

Finally, to try to improve the synthesis process of the nanoparticles during the enzymatic reaction, $\mathrm{SiO}_{2}$ nanoparticles were added. This was intended to generate nuclei from which the gold nanoparticles grow. However, no modifications of the kinetic were observed (Figure S7).

\subsection{Analytical figures of merit}

The optimum experimental conditions for tyramine determination derived from the studies described above are compiled in Table 1. The experimental linear response range (Figure S8), the detection (LOD) and quantification limit (LOQ) and the RSD 
obtained are also compiled, working at room temperature (rt) and at $40{ }^{\circ} \mathrm{C}$ degrees. It is important to indicate that the detection limit of this method is consistent with that obtained using the classical HRP/colorant reaction.

\subsection{Interferences}

Other amines have been studied as possible interferences in the method. To this end, putrescine, cadaverine and histamine, the main biogenic amines appearing with tyramine in real samples, were studied. Our experimental studies have shown that these three biogenic amines were not able to generate AuNP during the enzymatic reaction (at least up to $\left.10^{-4} \mathrm{M}\right)$. However, they affect the AuNP formation during the tyramine /TAO reaction.

First, figure S9A show the $\mathrm{Abs}_{540 \mathrm{~nm}}=\mathrm{f}(\mathrm{t})$ representations obtained for tyramine in the presence of putrescine and cadaverine. As can be seen, both amines decrease the rate of the AuNP formation during the reaction but the final absorbance is not affected. Figure S9B shows that the kinetic of the $\mathrm{O}_{2}$ consumption by the tyramine /TAO reaction is not affected by any of the amines, so the most plausible interference mechanism comes from the ability of $\mathrm{Au}(\mathrm{III})$ to form coordination complexes with diamines, $\left(\mathrm{Au}(\mathrm{Put}) 2^{3+}\right.$ and $\mathrm{Au}(\mathrm{Cad})_{2}{ }^{3+}$ being the expected stoichiometries [34]). These complexes decrease the kinetic of the $\mathrm{Au}(\mathrm{III})$ reduction. In order to correct this problem, several alternatives were examined. The easiest to use was increasing the kinetic of the reaction by heating at temperature of about $40{ }^{\circ} \mathrm{C}$ (figure $\mathrm{S} 9 \mathrm{C}$ ).

A more important problem was caused by the histamine:tyramine ratio. If this ratio is $1: 1$, the formation of nanoparticles is not observed. The general hypothesis is that histamine forms a complex, stronger than those of the putrescine or cadaverine with $\mathrm{Au}(\mathrm{III})$ that does not allow it to react following the mechanism described above [35]. This interference was not avoided by heating the solution or by adding a metallic 
species $(\mathrm{Cu}(\mathrm{II})$ or $\mathrm{Zn}(\mathrm{II}))$ able to react with histamine. To evaluate the magnitude of this interference, tests were performed with a constant concentration of tyramine and varying the amounts of histamine present in the reaction. Figure S10A shows the absorption spectra obtained. It can be observed that the decrease in the signal is proportional to the histamine presents in the sample (Figure S10B). This type of interference can be estimated by performing a doping of the sample with a known concentration of tyramine and observing how the signal decreases depending on the amount of histamine present.

\subsection{Real sample}

Many types of samples contain tyramine as the majority biogenic amine. An example is Emmental cheese, so we applied this method to tyramine determination in a sample of this cheese.

Using the optimized experimental conditions (and working at $40{ }^{\circ} \mathrm{C}$ ), we applied the method explained in the experimental section and the standard addition method to avoid interferences of the matrix. In Figure S11 it can be seen that the slope of the line does not differ significantly from the slope of the line for which no sample is added, so no proportional interferences were observed. The concentration of tyramine in the sample obtained was $93 \pm 14 \mathrm{mg} \mathrm{Kg}^{-1}(\mathrm{n}=5)$. The sample was also analyzed by the Public Health Laboratory of Aragón using their HPLC validated method ( $\left.86 \pm 13 \mathrm{mg} \mathrm{Kg}^{-1}, \mathrm{n}=3\right)$ and a colorimeter method based on TAO but using $\mathrm{HRP} / \mathrm{TMB}$ as the indicating reaction (see Appendix S3). No significant differences were observed between the methods.

\section{CONCLUSIONS}

This paper has demonstrated the possibility of generating AuNP during an enzymatic reaction and using the corresponding plasmon resonance band as the analytical signal, thus avoiding, in this way, the chromogen/HRP indicating reaction. Although several 
theoretical aspects need more in-depth studies, the results suggest that this is a general mechanism which can work with many other enzymatic reactions. Moreover, other types of analytical signals deserve to be studied, such as: the fluorescence of gold nanoclusters, which is expected to appear during the nucleation process, and/or the surface-enhanced Raman signal of the enzyme or the reaction product, as a consequence of the AuNP formation. Finally, this method may also be carried out using other types of metallic species able to generate nanoparticles (especially, $\mathrm{Ag}(\mathrm{I})$ ). 


\section{REFERENCES}

1. Benkerroum, N (2016) Biogenic amines in dairy products: origin, incidence, and control means. Compr Rev Food Sci F 15:801-826. https://doi.org/10.1111/15414337.12212

2. Karovičová, J, Kohajdová, Z (2005) Biogenic amines in food. Chem Pap 59: 70-79.

3. Papageorgiou, M, Lambropoulou, D, Morrison, C, Kłodzińska, E, Namieśnik, J, PłotkaWasylka, J (2018) Literature update of analytical methods for biogenic amines determination in food and beverages. Trac-Trend Anal Chem 98:128-142. https://doi.org/10.1016/j.trac.2017.11.001

4. Ordóñez, JL, Troncoso, AM, García-Parrilla, MDC, Callejón, RM (2016) Recent trends in the determination of biogenic amines in fermented beverages-A review. Anal Chim Acta 939:10-25. https://doi.org/10.1016/j.aca.2016.07.045

5. Wouters, J, Perpete, P, Hayen, P, Anceau, N, Durant, F (1994) Kinetic characterization of tyramine oxidase of Arthrobacter species. Biochem Mol Biol Int 32:737-743.

6. Lata, S, Yadav, S, Bhardwaj, R, Pundir, CS (2011) Amperometric determination of tyramine in sauce and beer by epoxy resin biocomposite membrane bound tyramine oxidase. Sens \& Instrument Food Qual 5:104-110. https://doi.org/10.1007/s11694-011$9117-5$

7. Lange, J, Wittmann, C (2002) Enzyme sensor array for the determination of biogenic amines in food samples. Anal Bioanal Chem 372:276-283. https://doi.org/10.1007/s00216001-1130-9

8. Osman, AM, Wong, KKY, Fernyhough, A (2006) ABTS radical-driven oxidation of polyphenols: Isolation and structural elucidation of covalent adducts. Biochem Bioph Res Co 346:321-329. https://doi.org/10.1016/j.bbrc.2006.05.118

9. Scott, SL, Chen, WJ, Bakac, A, Espenson, JH (1993) Spectroscopic parameters, electrode potentials, acid ionization constants, and electron exchange rates of the 2, 2'-azinobis (3- 
ethylbenzothiazoline-6-sulfonate) radicals and ions. J Phys Chem 97:6710-6714. https://doi.org/10.1021/j100127a022

10. Zamborini, FP, Bao, L, Dasari, R (2011) Nanoparticles in measurement science. Anal Chem 84:541-576. https://doi.org/10.1021/ac203233q

11. Sabela, M, Balme, S, Bechelany, M, Janot, JM, Bisetty, K (2017) A review of gold and silver nanoparticle-based colorimetric sensing assays. Adv Eng Mater 9:1700270. https://doi.org/10.1002/adem.201700270

12. Liu, BW, Wu, YY, Huang, PC, Wu, FY (2019) Colorimetric determination of cytosine-rich ssDNA by silver (I)-modulated glucose oxidase-catalyzed growth of gold nanoparticles. Microchim Acta, 186:467. https://doi.org/10.1007/s00604-019-3591-6

13. Li, G, Yang, M, Chen, LC, Gao, B, Xiong, XL (2015) Colorimetric and visual detection of tyrosine based on its copper-catalyzed enzymatic oxidation to dopamine and subsequent reductive formation of colored gold nanoparticles using copper ions. Microchim Acta, 182:13-117. https://doi.org/10.1007/s00604-014-1278-6

14. López-Lorente, AI, Valcárcel, M (2016) The third way in analytical nanoscience and nanotechnology: Involvement of nanotools and nanoanalytes in the same analytical process. Trac-Trend Anal Chem 75:1-9. https://doi.org/10.1016/j.trac.2015.06.011

15. Xie, J, Zheng, Y, Ying, JY (2009) Protein-directed synthesis of highly fluorescent gold nanoclusters. J Am Chem Soc 131:888-889. https://doi.org/10.1021/ja806804u

16. Newman, JDS, Blanchard, GJ (2006) Formation of gold nanoparticles using amine reducing agents. Langmuir 22:5882-5887. https://doi.org/10.1021/la060045z

17. Bai, J, Flowers, K, Benegal, S, Calizo, M, Patel, V, Bishnoi, SW (2009) Using the enzymatic growth of nanoparticles to create a biosensor. An undergraduate quantitative analysis experiment. J Chem Educ 86:712. https://doi.org/10.1021/ed086p712

18. Alonso-de Castro, S, Cortajarena, AL, López-Gallego, F, Salassa, L (2018) Bioorthogonal catalytic activation of platinum and ruthenium anticancer complexes by FAD and flavoproteins. Angew Chem Int Edit 130:3197-3201.

https://doi.org/10.1002/ange.201800288 
19. Quist, DA, Diaz, DE, Liu, JJ, Karlin, KD (2017) Activation of dioxygen by copper metalloproteins and insights from model complexes. Jbic J Biol Inorg Chem 22:253-288. https://doi.org/10.1007/s00775-016-1415-2

20. Thanh, NT, Maclean, N, Mahiddine, S (2014) Mechanisms of nucleation and growth of nanoparticles in solution. Chem Rev 114:7610-7630. https://doi.org/10.1021/cr400544s

21. You, H, Fang, J (2016) Particle-mediated nucleation and growth of solution-synthesized metal nanocrystals: a new story beyond the LaMer curve. Nano Today 11:145-167. https://doi.org/10.1016/j.nantod.2016.04.003

22. Watzky, MA, Finke, RG (1997) Transition metal nanocluster formation kinetic and mechanistic studies. A new mechanism when hydrogen is the reductant: slow, continuous nucleation and fast autocatalytic surface growth. J Am Chem Soc 119:10382-10400. https://doi.org/10.1021/ja9705102

23. Finney, EE, Finke, RG (2008) Nanocluster nucleation and growth kinetic and mechanistic studies: A review emphasizing transition-metal nanoclusters. J Colloid Interf Sci 317:351374. https://doi.org/10.1016/j.jcis.2007.05.092

24. Brazeau, AL, Jones, ND (2009) Growth Mechanisms in Nanocrystalline Lead Sulfide by Stopped-Flow Kinetic Analysis. J Phys Chem C 113:20246-20251. https://doi.org/10.1021/jp907270x

25. Shields, SP, Richards, VN, Buhro, WE (2010) Nucleation control of size and dispersity in aggregative nanoparticle growth. A study of the coarsening kinetics of thiolate-capped gold nanocrystals. Chem Mater 22:3212-3225. https://doi.org/10.1021/cm100458b

26. Burda, C, Chen, X, Narayanan, R, El-Sayed, MA (2005) Chemistry and properties of nanocrystals of different shapes. Chem Rev 105:1025-1102. https://doi.org/10.1021/cr030063a

27. Enoch, S, Quidant, R, Badenes, G (2004) Optical sensing based on plasmon coupling in nanoparticle arrays. Opt Express 12:3422-3427. https://doi.org/10.1364/OPEX.12.003422 
28. Haiss, W, Thanh, NT, Aveyard, J, Fernig, DG (2007) Determination of size and concentration of gold nanoparticles from UV- Vis spectra. Anal Chem 79:4215-4221. https://doi.org/10.1021/ac0702084

29. Khlebtsov, NG (2008) Determination of size and concentration of gold nanoparticles from extinction spectra. Anal Chem 80:6620-6625. https://doi.org/10.1021/ac800834n

30. Shi, X, Li, D, Xie, J, Wang, S, Wu, Z, Chen, H (2012) Spectroscopic investigation of the interactions between gold nanoparticles and bovine serum albumin. Chinese Sci Bull 57:1109-1115. https://doi.org/10.1007/s11434-011-4741-3

31. Liu, X, Atwater, M, Wang, J, Huo, Q (2007) Extinction coefficient of gold nanoparticles with different sizes and different capping ligands. Colloid Surface B 58:3-7. https://doi.org/10.1016/j.colsurfb.2006.08.005

32. Jain, PK, Lee, KS, El-Sayed, IH, El-Sayed, MA (2006) Calculated absorption and scattering properties of gold nanoparticles of different size, shape, and composition: applications in biological imaging and biomedicine. J Phys Chem B 110:7238-7248. https://doi.org/10.1021/jp057170o

33. Leff, DV, Ohara, PC, Heath, JR, Gelbart, WM (1995) Thermodynamic control of gold nanocrystal size: experiment and theory. J Phys Chem 99:7036-7041. https://doi.org/10.1021/j100018a041

34. Mironov, IV, Afanas'eva, VA (2010) Gold (III) amine complexes in aqueous alkali solutions. Russ J Inorg Chem+ 55:1156-1161. https://doi.org/10.1134/S0036023610070302

35. Sjöberg, S (1997) Critical evaluation of stability constants of metal-imidazole and metalhistamine systems (Technical Report). Pure Appl Chem 69:1549-1570. https://doi.org/10.1351/pac199769071549 
Table 1. Analytical figures of merit obtained working at room temperature $\left(20^{\circ} \mathrm{C}\right)$ and $40{ }^{\circ} \mathrm{C}$. ${ }^{\$}$ The RSD obtained for all points of the calibration line linearly decrease from $11.3 \%$ (rt) or $11.8 \%\left(40{ }^{\circ} \mathrm{C}\right.$ ) obtained for $25 \mu \mathrm{M}$ to $3.2 \%$ (rt) or $4.0 \%\left(40{ }^{\circ} \mathrm{C}\right.$ ) obtained using $330 \mu \mathrm{M}$

\begin{tabular}{|l|c|c|}
\hline & $\mathbf{2 0}^{\mathbf{}} \mathbf{C}(\mathbf{r t})$ & $\mathbf{4 0}^{\mathbf{}} \mathbf{C}$ \\
\cline { 1 - 1 } Linear range, $\boldsymbol{\mu M}$ & $25-330$ & $25-330$ \\
\cline { 1 - 1 } LOQ, $\boldsymbol{\mu M}$ & 9.5 & 11.5 \\
\cline { 1 - 1 } LOD, $\boldsymbol{\mu M}$ & 2.9 & 3.4 \\
\cline { 1 - 1 } & \multirow{2}{*}{$5.6(\mathrm{n}=5)$} & \multirow{2}{*}{$6.0(\mathrm{n}=5)$} \\
\hline
\end{tabular}




\section{FIGURE CAPTIONS}

Scheme 1. Enzymatic oxidation of tyramine catalyzed by Tyramine Oxidase (subscript "ox" and "red" refer to oxidized and reduced forms of TAO, respectively).

Figure 1. Molecular abosortion spectra of gold nanoparticles (AuNP) formation during the enzymatic reaction. Experimental conditions: $[\mathrm{TAO}]=0.5 \quad \mathrm{U} \cdot \mathrm{mL}^{-1}, \quad[\mathrm{Au}(\mathrm{III})]=1 \mathrm{mM}$, [tyramine] $=2.6 \times 10^{-4} \mathrm{M}$, incubation time $5 \mathrm{~min}$ and $\mathrm{pH} 7.0$ phosphate buffer $0.1 \mathrm{M}$, at room temperature (Figure 1B shows the absorbance at the maximum wavelength).

Figure 2. Effect of the incubation time on the kinetic of the AuNP formation a) $0 \mathrm{~min}$; b) $1 \mathrm{~min}$; c) 3 min; d) $5 \mathrm{~min}$; e) $8 \mathrm{~min}$. Experimental conditions: [TAO] $=0.5 \mathrm{U} \cdot \mathrm{mL}^{-1},[\mathrm{Au}(\mathrm{III})]=1 \mathrm{mM}$, [tyramine $]=2.6 \times 10^{-4} \mathrm{M}$ and $\mathrm{pH} 7.0$ phosphate buffer $0.1 \mathrm{M}$, at room temperature.

Figure 3. Effect of the TAO concentration on the absorption spectra of the formed AuNP a) 0.2 U.mL ${ }^{-1}$; b) $\left.0.5 \mathrm{U} \cdot \mathrm{mL}^{-1} \mathrm{c}\right) 1.0 \mathrm{U} \cdot \mathrm{mL}^{-1}$; d) $2 \mathrm{U} \cdot \mathrm{mL}^{-1}$; e) $4 \mathrm{U} \cdot \mathrm{mL}^{-1}$. Experimental conditions: [Au(III)]=1 $\mathrm{mM}$, [tyramine] $=2.6 \times 10^{-4} \mathrm{M}$, incubation time $5 \mathrm{~min}$ and $\mathrm{pH} 7.0$ phosphate buffer $0.1 \mathrm{M}$, at room temperature.

Figure 4. Effect of the temperature on the kinetic of the reaction a) $20{ }^{\circ} \mathrm{C}$; b) $30{ }^{\circ} \mathrm{C}$; c) $40{ }^{\circ} \mathrm{C}$; d) 50 ${ }^{\circ} \mathrm{C}$; e) $60{ }^{\circ} \mathrm{C}$. Experimental conditions: $[\mathrm{TAO}]=0.5 \mathrm{U} \cdot \mathrm{mL}^{-1},[\mathrm{Au}(\mathrm{III})]=1 \mathrm{mM}$, [tyramine $]=7.9 \times 10^{-4} \mathrm{M}$, incubation time $5 \mathrm{~min} 3$ and $\mathrm{pH} 7.0$ phosphate buffer $0.1 \mathrm{M}$.

\section{Scheme 1}

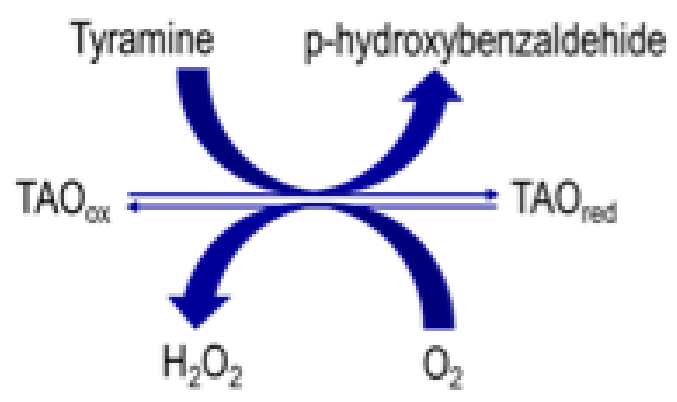


Figure 1
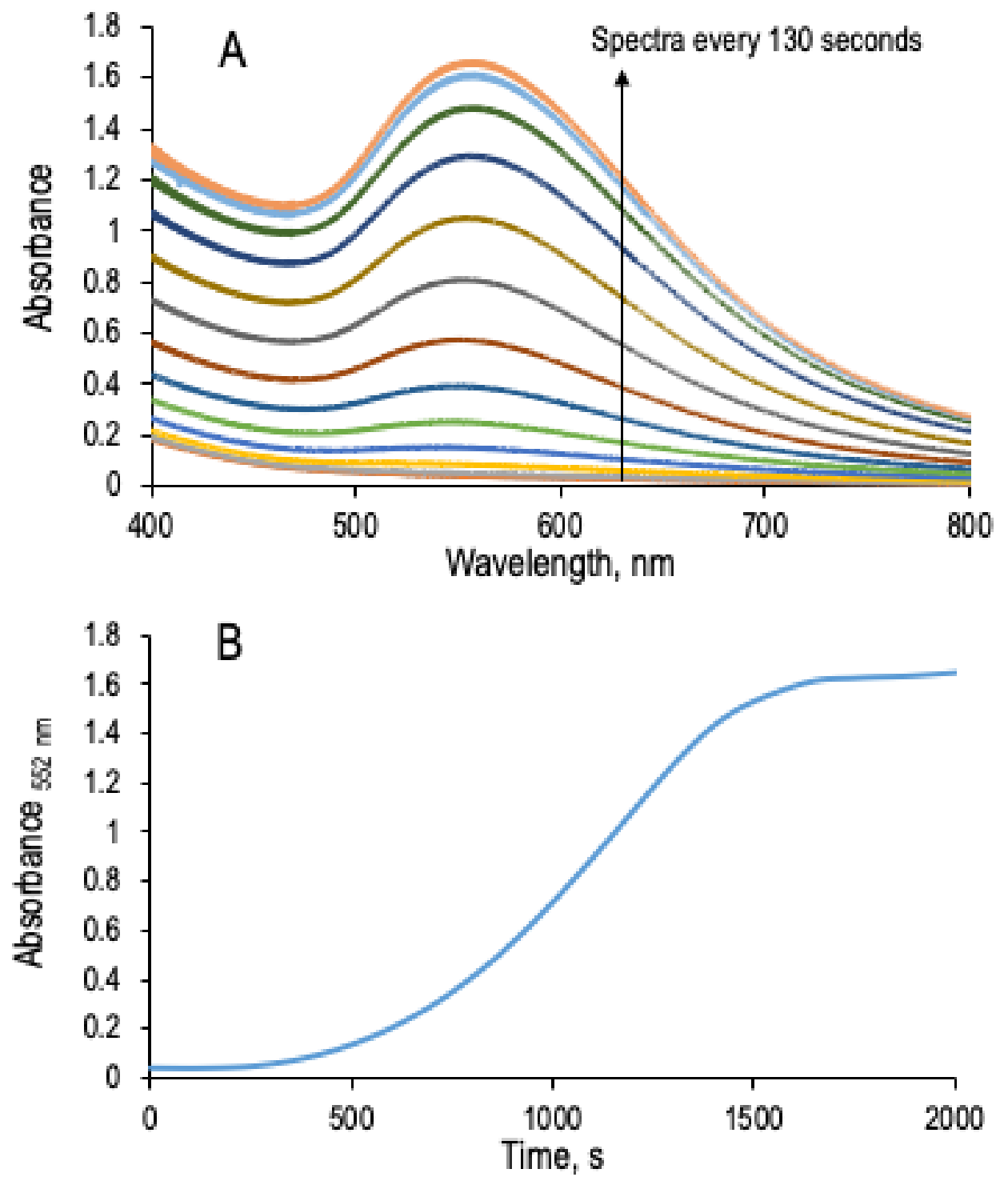
Figure 2

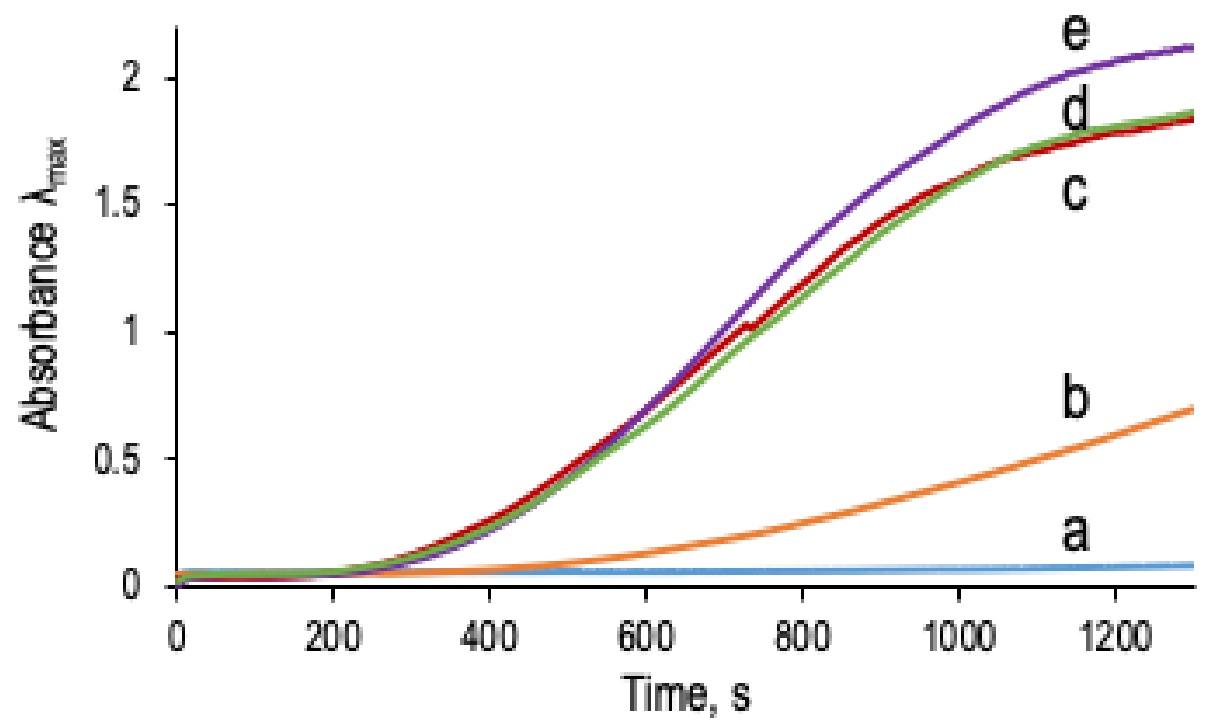


Figure 3

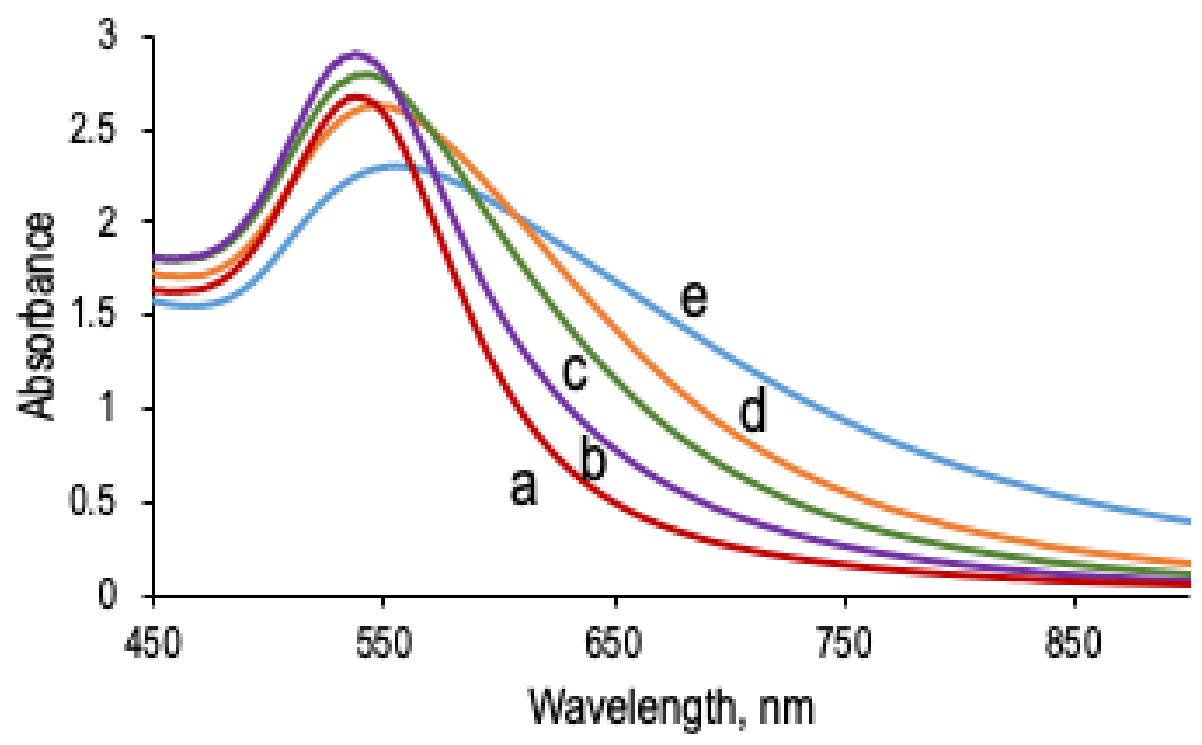


Figure 4

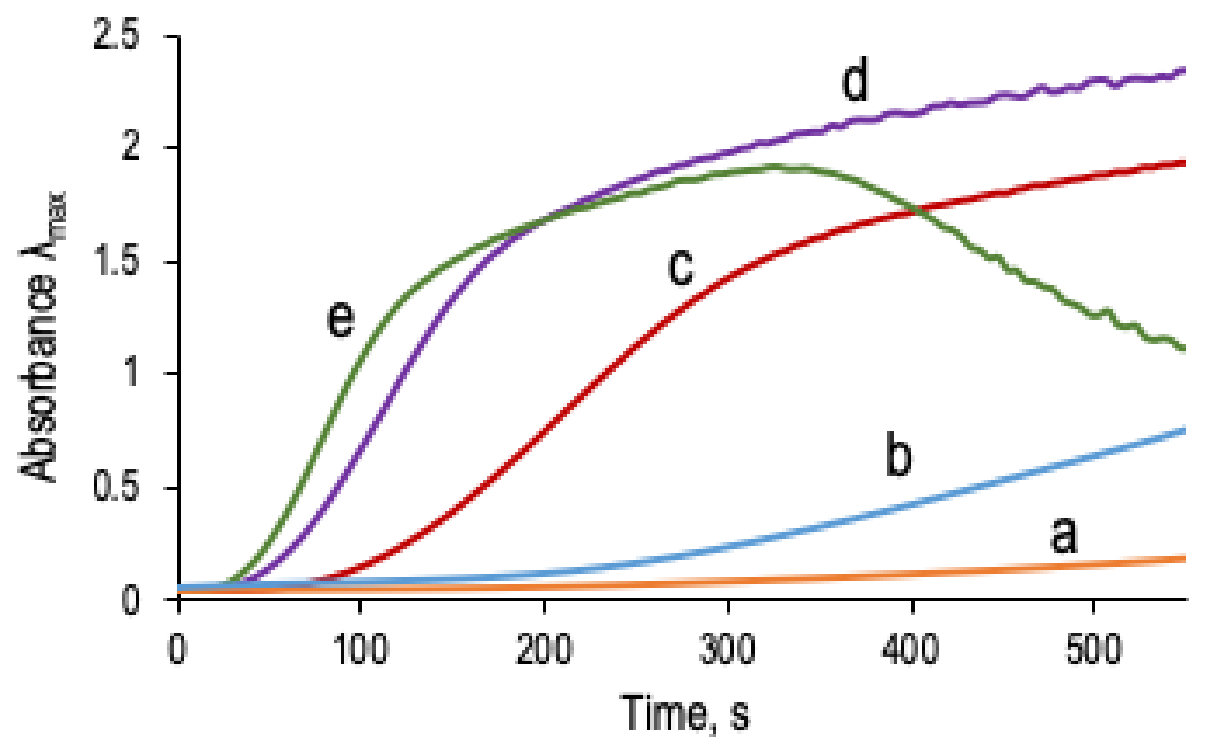


Graphical Abstract: Tyramine is determined by measuring the plasmon band of the gold nanoparticles formed during its enzymatic reaction with Tyramine oxidase. Moreover, a mathematical model has been developed to explain the formation of the gold nanoparticles during the reaction.

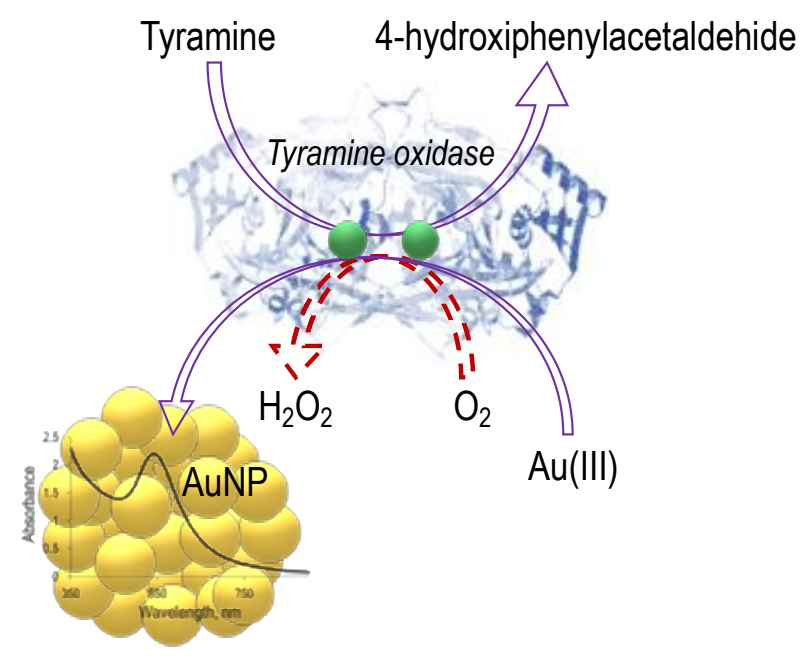

